\title{
Interspecific Variation in Temperature Effects on Embryonic Metabolism and Development in Turtles
}

\author{
Day B. Ligon', ${ }^{1}$ and Matthew B. Lovern ${ }^{1}$ \\ ${ }^{1}$ Department of Zoology, Oklahoma State University, Stillwater, OK 74078, USA \\ ${ }^{2}$ Department of Biology, Missouri State University, 901 South National, Springfield, MO 65897, USA
}

Correspondence should be addressed to Day B. Ligon, dayligon@missouristate.edu

Received 22 November 2011; Accepted 25 December 2011

Academic Editors: P. V. Lindeman and P. Scaps

Copyright (C 2012 D. B. Ligon and M. B. Lovern. This is an open access article distributed under the Creative Commons Attribution License, which permits unrestricted use, distribution, and reproduction in any medium, provided the original work is properly cited.

\begin{abstract}
We measured temperature-induced differences in metabolic rates and growth by embryos of three turtle species, Macrochelys temmincki, Trachemys scripta, and Apalone spinifera, at different, constant, temperatures. Oxygen consumption rate $\left(\mathrm{VO}_{2}\right) \mathrm{was}$ measured during development and used to characterize changes in metabolism and calculate total $\mathrm{O}_{2}$ consumption. Results from eggs incubated at different temperatures were used to calculate $\mathrm{Q}_{10} \mathrm{~s}$ at different stages of development and to look for evidence of metabolic compensation. Total $\mathrm{O}_{2}$ consumption over the course of incubation was lowest at high incubation temperatures, and late-term metabolic rate $\mathrm{Q}_{10} \mathrm{~s}$ were $<2$ in all three species. Both results were consistent with positive metabolic compensation. However, incubation temperature effects on egg mass-corrected hatchling size varied among species. Apalone spinifera hatchling mass was unaffected by temperature, whereas T. scripta mass was greatest at high temperatures and M. temminckii mass was lowest at high temperatures. Hatchling mass: length relationships tended to correlate negatively with temperature in all three species. Although we cannot reject positive metabolic compensation as a contributor to the observed $\mathrm{VO}_{2}$ patterns, there is precedence for drawing the more parsimonious conclusion that differences in yolk-free size alone produced the observed incubation temperature differences without energetic canalization by temperature acclimation during incubation.
\end{abstract}

\section{Introduction}

Although the suite of biochemical activities that contributes to an organism's metabolism is complex and therefore challenging to model [1], strong relationships exist between body temperature and whole-organism metabolic rate [2]. Various thermoregulatory mechanisms are employed by animals to dissociate body temperature from ambient temperature. Endothermy has evolved repeatedly as a physiological means of surviving suboptimal thermal conditions, but ectothermic species often rely primarily on behavioral strategies to regulate body temperature. In addition to behavior, however, ectotherms may exhibit physiological mechanisms to address thermal constraints of their environment. Solutions for surviving inhospitable temperatures may include manipulating biochemical reaction rates by varying enzyme concentrations or receptor densities, production of chaperone proteins to increase the range of temperatures over which target enzymes remain functional [3], changing the composition of cell membranes to affect permeability and (rarely) producing temperature-specific isozymes [4-6].

In comparison to other life stages when behavior can play an important role in overcoming thermal constraints, means for maintaining suitable body temperatures of oviparous animals during embryonic development are limited. Three factors contribute minimizing an embryo's exposure to or effects of suboptimal thermal conditions: (1) indirect behavioral temperature selection via maternal thermoregulation or nest-site selection; (2) developmental diapause during periods when thermal conditions are unsuitable; (3) utilization of one or more of the physiological strategies listed above. These strategies may function alone or in combination to circumvent thermal limitations on development. For example, because the efficacy of maternal nest-site choice may be limited by the stochastic nature of environmental temperatures [7], maternal nest-site selection seems likely to 
function in combination with complementary physiological compensatory strategies.

Much attention has been paid to the effects of temperature on hatchling traits, particularly among taxa that exhibit temperature-dependent sex determination. In addition to effects on population sex ratios in many species [8-10], temperature has been demonstrated to influence hatchling size, posthatching growth, locomotor performance, metabolic rate, agility, and crypsis [11-28]. The ways in which temperatures during embryonic development affect postembryonic endpoints have received more attention among reptiles than have endpoints measured during embryonic development [29]. Thus, some aspects of how differences in the thermal environment experienced by embryos lead to morphological and performance differences remain poorly understood.

The finite quantity of energy and materials packaged in an egg must be budgeted to meet development and growth requirements. Therefore, temperature-induced differences in energy utilization could trickle down to affect posthatching condition of offspring by directly or indirectly influencing morphology, physiological performance, or postembryonic energy reserves. The effects of temperature on embryo metabolism have been studied in a variety of reptiles [3036]. Patterns in the relationship between temperature and embryo energy expenditure have been fairly consistent. For example, Angilletta et al. [33] found that, in the lizard Sceloporus undulatus, energy expenditure over the course of incubation was similar at $30^{\circ}, 32^{\circ}$, and $34^{\circ} \mathrm{C}$, but 10 $15 \%$ lower compared to embryos that developed at $28^{\circ} \mathrm{C}$. Similarly, Crocodylus johnstoni embryos consumed 10\% less oxygen at $31^{\circ} \mathrm{C}$ than at $29^{\circ} \mathrm{C}$ [37], and embryonic Nile soft shell turtles (Trionyx triunguis) incubated at $27^{\circ}$ and $30^{\circ} \mathrm{C}$ exhibited similar energetic expenditure, but used 5\% less oxygen at $33^{\circ} \mathrm{C}$ [38]. In contrast to this pattern of lower oxygen consumption at higher temperatures, no effect of incubation temperature was observed among Emydura signata embryos incubated at $24^{\circ}$ and $31^{\circ} \mathrm{C}$ [39] or Chelonia mydas incubated at $26^{\circ}$ and $30^{\circ} \mathrm{C}[40]$.

In combination, these studies suggest that embryos of many reptiles utilize less energy during development at higher incubation temperatures, but some species may exhibit a capacity to physiologically correct for suboptimally high or low body temperatures, commonly referred to as positive compensation $[4,41]$. The goal of this study was to investigate differences in incubation temperature effects on embryonic development and metabolism among a sympatric but phylogenetically diverse assemblage of freshwater turtles [42]: Trachemys scripta; Apalone spinifera; Macrochelys temminckii. Our objectives were threefold. The first was to measure the capacity for metabolic compensation during embryonic development by comparing stage-specific $\mathrm{VO}_{2}$ (oxygen consumption rate) of embryos exposed to different constant incubation temperatures. These measurements were then used to calculate differences in $\mathrm{Q}_{10}$ (the rate of change of a physiological process as a consequence of increasing the temperature by $10^{\circ} \mathrm{C}$ ) at different stages of development. Second, we evaluated temperature effects on energetic cost of development by calculating the total volume of oxygen $\left(\mathrm{O}_{2 \text { total }}\right)$ used over the course of incubation, and mass-conversion efficiency based on differences in hatchling mass after correcting for variation in initial egg mass. Third, we qualitatively assessed the degree of variation in different species' responses to temperature.

\section{Materials and Methods}

All procedures for this research were approved by the Oklahoma State University Institutional Animal Care and Use Committee (Protocol AS023), guaranteeing compliance with animal care guidelines described in The Guide for the Care and Use of Laboratory Animals, 7th edition (1996). Trachemys scripta and M. temminckii hatchling mass data were used in other analyses related to posthatching effects of $T_{\text {inc }}$ (incubation temperature) [43].

2.1. Study Species. The three turtle species included in this study represent three different families and, although sympatric in parts of their range, they exhibit substantial ecological differences. Trachemys scripta (Family Emydidae) is medium in size and primarily aquatic but engages in frequent basking and terrestrial migrations between water bodies and conforms to the Type Ia pattern of temperature-dependent sex determination [44], wherein males are produced at low temperatures and females at high temperatures. Apalone spinifera (Family Trionychidae) exhibits many adaptations to a pelagic lifestyle, including a hydrodynamic form and substantial capacity for aquatic respiration. In contrast to most turtles, sex is determined genetically in members of this family [45]. Finally, Macrochelys temminckii (Family Chelydridae) is a very large-bodied, primarily bottomdwelling species that seldom leaves water except to nest. It follows a type II pattern of temperature-dependent sex determination, characterized by development of females at low and high temperatures, and males or a mixed sex ratio at intermediate temperatures [44].

2.2. Egg Collection. Eggs were obtained for all three species in May and June 2004. A single A. spinifera nest was excavated from a sand bar at Sequoyah National Wildlife Refuge (SNWR) in eastern Oklahoma, and transported to Oklahoma State University (OSU) within $15 \mathrm{~h}$ after deposition. Gravid T. scripta were trapped in an oxbow at SNWR using baited hoop nets. These turtles were transported to OSU where oviposition was induced using oxytocin $(0.10 \mathrm{IU} / \mathrm{kg} \mathrm{IM})$ [46]. Turtles were placed individually in plastic tubs containing approximately $15 \mathrm{~cm}$ of water to minimize accidental destruction of eggs by the turtles. After eggs were obtained, the adult females were released at SNWR. Finally, M. temminckii eggs were obtained from a captive group maintained at Tishomingo National Fish Hatchery as part of a captive breeding/reintroduction program. The adult turtles which produced the eggs for this study originated from SNWR. Eggs were laid naturally and excavated from nests within two $d$ following oviposition. No eggs of any of the three species showed signs of the white banding characteristic of early development [47] prior to arriving at OSU. 
2.3. Incubation. Eggs from each species were measured $( \pm 0.1 \mathrm{~mm})$ and weighed $( \pm 0.01 \mathrm{~g})$, and then assigned to an incubation treatment in a randomized block design (block $=$ clutch). Within each incubation treatment, eggs were distributed among 1-5 plastic shoeboxes $(1.5 \mathrm{~L})$ halffilled with damp vermiculite (1:1 vermiculite: water by mass; $\sim-150 \mathrm{kPa}$ water tension; [48]). Shoeboxes were then assigned to one of three constant-temperature incubators set at $26.5^{\circ}, 28.5^{\circ}$, and $30.5^{\circ} \mathrm{C}$. Boxes were rotated within each incubator daily to eliminate the possibility of position effects, and each box was weighed weekly and rehydrated as necessary to maintain its initial mass. Eggs were candled every 2-3 days during early development and eggs that failed to develop were discarded to eliminate substrate for invasion of mold.

2.4. Hatchlings. Upon pipping, each egg was placed in a plastic jar lined with dampened paper towels so that the identity of individuals could be determined after hatching. After emerging from the egg shell, hatchlings were kept in the plastic jars until residual yolks were completely internalized, a period that lasted $0-9 \mathrm{~d}$ and varied among species. Apalone spinifera were photographed and T. scripta and $M$. temminckii received unique markings to ensure future identification. Cuticle scissors were used to cut notches in unique combinations of marginal scutes on T. scripta. A small sewing needle was used to tie small loops of dental floss through unique combinations of scutes on $M$. temminckii [27]. Hatchlings were removed from the incubator to flowthrough raceways.

2.5. Metabolic Rate. Metabolic rates were estimated by measuring changes in oxygen concentration in chambers via closed system respirometry [49] and calculating $\mathrm{VO}_{2}$ [50]. Eggs were placed individually in metabolic chambers constructed from $169 \mathrm{~mL}$ plastic jars with screw-top lids. A stopcock was inserted through each lid and sealed in place with silicon. Initial air samples were drawn from each chamber into stopcock-equipped $30 \mathrm{cc}$ syringes, and then sealed. The chambers were then placed into the incubators for 1-1.5 h (longer during early development when $\mathrm{VO}_{2}$ was expected to be low). Chambers were then removed from the incubator, and final air samples were drawn into a second set of syringes. Eggs were weighed at the conclusion of each measurement and returned to the plastic shoeboxes.

Oxygen concentrations of all air samples were analyzed in $10 \mathrm{~mL}$ aliquots with a Sable Systems FC-1 oxygen analyzer. A stream of air was drawn from outside the building at a regulated flow rate of $100 \mathrm{~mL} / \mathrm{min}$. It passed through serial columns of Drierite and Ascarite to remove water and $\mathrm{CO}_{2}$, respectively. Each aliquot was injected into the air stream, which passed through a small column of Drierite and Ascarite and then through the oxygen analyzer. $\mathrm{VO}_{2}$ was calculated for each turtle as the difference between the initial and final volumes of oxygen after correcting for chamber volume [50].

$\mathrm{VO}_{2}$ of T. scripta and M. temminckii embryos was measured at $7 \mathrm{~d}$ intervals starting $7 \mathrm{~d}$ after oviposition. A. spinifera embryo $\mathrm{VO}_{2}$ was measured at 2-3 dintervals early and late in development, and on a $7 \mathrm{~d}$ schedule during the middle third of incubation.

The volume of oxygen used over the course of incubation was calculated for each turtle that successfully hatched by summing the trapezoidal areas created by adjacent $\mathrm{VO}_{2}$ measurements using the equation:

$$
\mathrm{O}_{2 \text { total }}=\frac{\sum^{i} 24\left(\mathrm{VO}_{2 n}+\mathrm{VO}_{2 n-1}\right)\left(T_{n}-T_{n-1}\right)}{2},
$$

where $\mathrm{O}_{2 \text { total }}$ was the oxygen consumed over the duration of incubation, $\mathrm{VO}_{2}$ was the rate of oxygen consumption at age $n$ measured in $\mathrm{mL} / \mathrm{h}, T$ was the number of days since the beginning of incubation, $n$ was the days on which $\mathrm{VO}_{2}$ was measured, and $p$ was day on which each turtle pipped. Because turtles hatched $0-7 \mathrm{~d}$ after the last embryo $\mathrm{VO}_{2}$ measurement, $\mathrm{VO}_{2 p}$ at the time of pipping was estimated based on the difference between $\mathrm{VO}_{2}$ measurements prior to and after hatching. These estimates were calculated as:

$$
\begin{aligned}
\mathrm{VO}_{2 p}= & {\left[\left(\mathrm{VO}_{2 \text { hatchling }}-\mathrm{VO}_{2 \text { final }}\right)\left(T_{\text {hatchling }}-T_{\text {final }}\right)^{-1}\right.} \\
& \left.\times\left(T_{\text {pip }}-T_{\text {final }}\right)\right]+\mathrm{VO}_{2 \text { final }},
\end{aligned}
$$

where $\mathrm{VO}_{2 \text { hatchling }}$ was measured at each hatchling's assigned incubation temperature following internalization of the residual yolk and $\mathrm{VO}_{2 \text { final }}$ was the last measurement prior to pipping. These values were used to calculate the final trapezoidal area of each turtle's $\mathrm{O}_{2 \text { total }}$ to produce a precise estimate of the volume of oxygen used between oviposition and hatching.

2.6. Statistics. Statistical analyses were conducted separately for each of the three species. Incubation temperature effects on three characteristics of $\mathrm{VO}_{2}$ during embryonic development were analyzed: timing of initial $\mathrm{VO}_{2}$ divergence; maximum $\mathrm{VO}_{2}\left(\mathrm{VO}_{2 \max }\right)$; developmental stage-specific $\mathrm{Q}_{10}$.

The age at which $\mathrm{VO}_{2}$ of embryos at different temperatures first diverged was assessed by performing post hoc comparisons using differences of least-squares means from a repeated measures ANCOVA across all measurements, with individual embryo's $\mathrm{VO}_{2} \mathrm{~s}$ repeated across measurement intervals and initial egg mass as a covariate.

$\mathrm{VO}_{2 \max }$ was likely affected by timing of measurements; therefore, timing of $\mathrm{VO}_{2 \max }$, expressed as a percentage of total incubation time, was included as a covariate in analyses comparing $\mathrm{VO}_{2 \max }$ at different incubation temperatures.

$\mathrm{Q}_{10}$ values were calculated at four different stages of development and were based on $\mathrm{VO}_{2}$ of embryos at 26.5 and $30.5^{\circ} \mathrm{C}$. Developmental stages were expressed as a percent of incubation time and were distributed such that $\mathrm{Q}_{10}$ was compared near the beginning, first and second thirds, and end of incubation.

Hatchling size was analyzed in two different ways: (1) mass was analyzed in an ANCOVA with initial egg mass as a covariate to assess incubation temperature effects on eggto-tissue mass conversion efficiency; (2) differences in body 
TABLE 1: Clutch, egg, and hatchling data for turtles included in this study (mean $\pm \mathrm{SE}$ ). Mean incubation periods are reported for eggs incubated at $26.5,28.5$, and $30.5^{\circ} \mathrm{C}$, respectively.

\begin{tabular}{lccccccc}
\hline Species & $\begin{array}{c}\text { Number of } \\
\text { Clutches }\end{array}$ & $\begin{array}{c}\text { Number of } \\
\text { eggs }^{\mathrm{a}}\end{array}$ & $\begin{array}{c}\text { Hatchling } \\
\text { success }(\%)\end{array}$ & $\begin{array}{c}\text { Incubation } \\
\text { period }(\mathrm{d})\end{array}$ & $\begin{array}{c}\text { Egg mass } \\
(\mathrm{g})\end{array}$ & $\begin{array}{c}\text { Hatchling } \\
\text { mass }(\mathrm{g})\end{array}$ & $\begin{array}{c}\text { Hatchling } \\
\text { length }(\mathrm{mm})^{\mathrm{b}}\end{array}$ \\
\hline A. spinifera & 1 & $18(18)$ & 89 & $77,61,53$ & $6.7 \pm 0.06$ & $4.4 \pm 0.06$ & $25.3 \pm 0.25$ \\
M. temminckii & 4 & $109(17-33)$ & 66 & $93,82,79$ & $26.1 \pm 0.18$ & $16.4 \pm 0.17$ & $35.2 \pm 0.17$ \\
T. scripta & 5 & $58(10-14)$ & 93 & $71,59,52$ & $11.5 \pm 0.08$ & $8.9 \pm 0.09$ & $32.1 \pm 0.11$ \\
\hline
\end{tabular}

${ }^{a}$ Number of eggs of each species used in this study, with clutch size range in parentheses.

${ }^{b}$ Plastron length reported for A. spinifera, carapace length reported for M. temminckii and T. scripta.

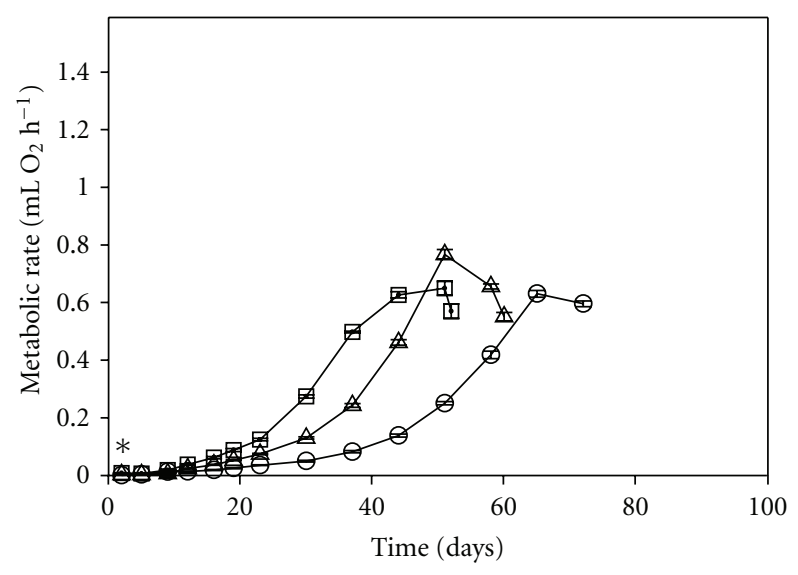

(a) Apalone spinifera

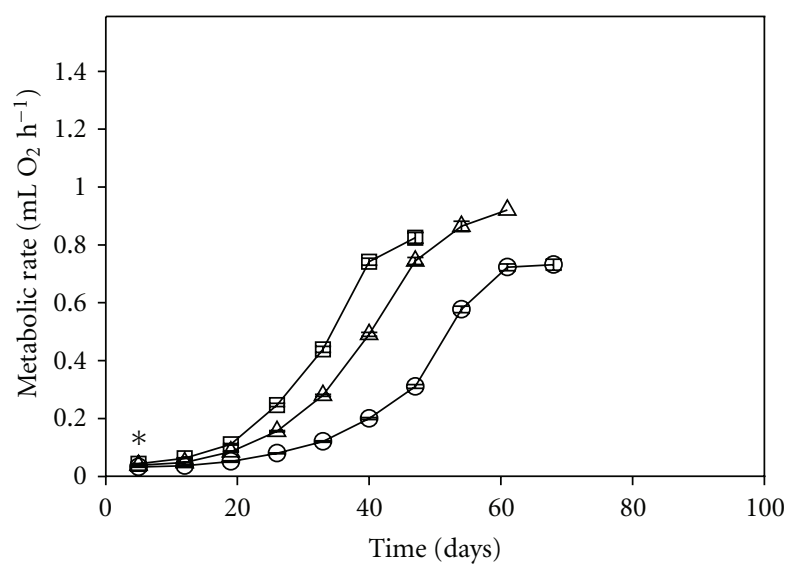

(b) Trachemys scripta

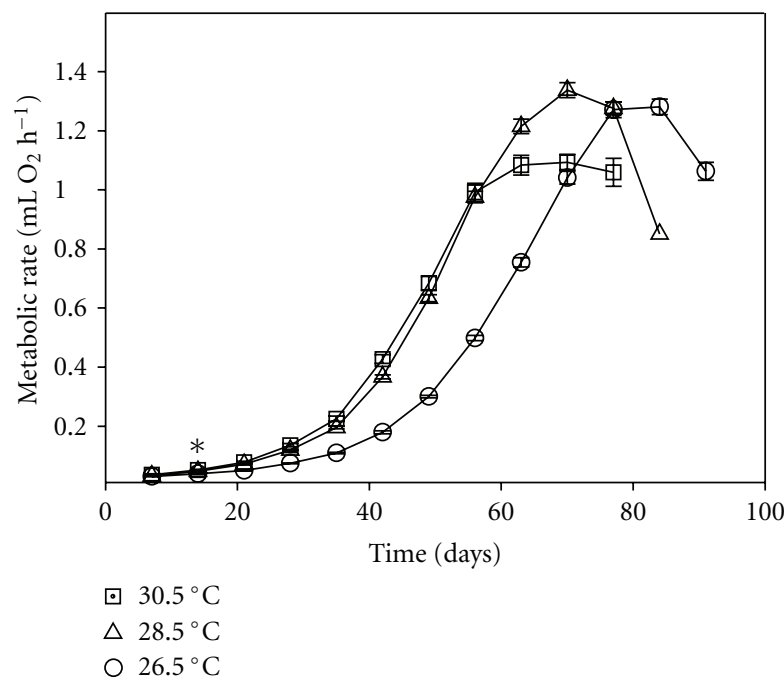

(c) Macrochelys temminckii

FIGURE 1: Changes in $\mathrm{VO}_{2}$ during embryonic development at three constant temperatures. Asterisks indicate first measurement at which $\mathrm{VO}_{2}$ diverged across all three incubation temperatures. Error bars $= \pm 1 \mathrm{SE}$.

length (carapace length was used for T. scripta and M. temminckii and plastron length was used for A. spinifera) were compared across incubation temperatures with hatchling mass as a covariate to assess differences in body composition (hereafter Body Condition Index, BCI).

In all of the above analyses, homogeneity of slopes among treatments was tested by comparing interaction terms that included the covariate. In all cases homogeneity was confirmed, and interaction terms were removed prior to final analyses. Also, nonsignificant covariates $(P>0.05)$ were removed to increase degrees of freedom for the error term. All statistical tests were conducted using SAS v. 9.1 Proc Mixed after testing the homogeneity of variance assumption using Proc GLM (SAS Institute 2002). All metabolism, 


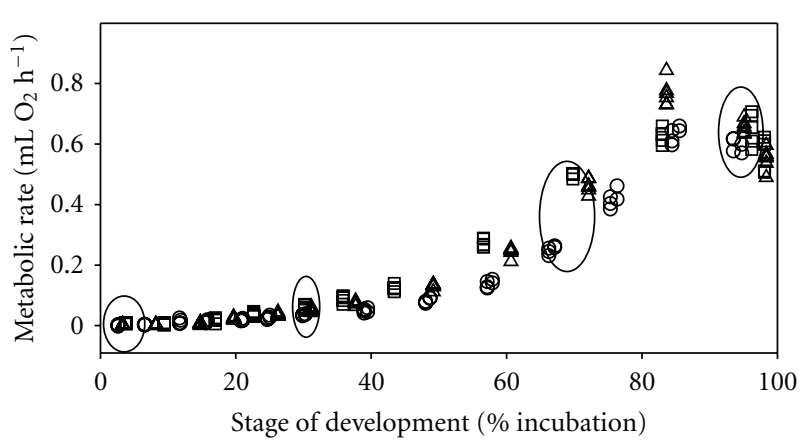

(a) Apalone spinifera

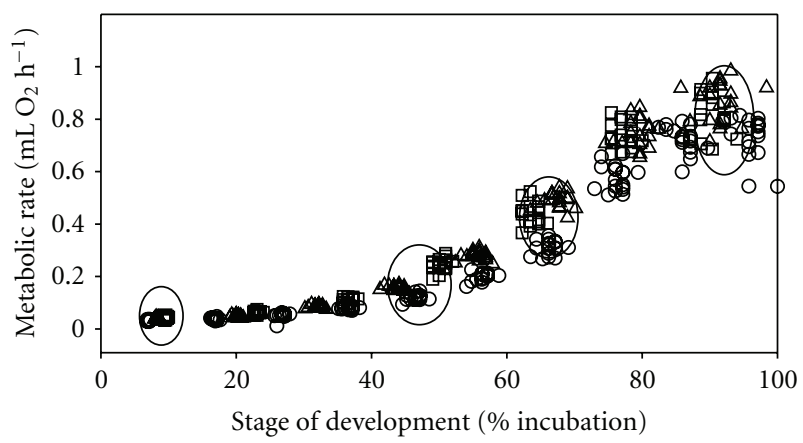

(b) Trachemys scripta

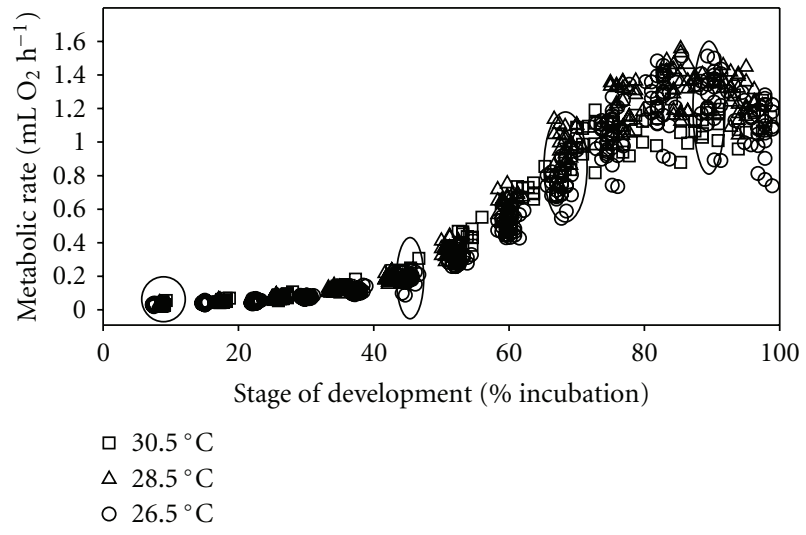

(c) Macrochelys temminckii

FIgURE 2: Comparison of changes in $\mathrm{VO}_{2}$ of embryos maintained at different temperatures, with time expressed as a percentage of total incubation duration. Ovals superimposed on each figure indicate samples used to calculate developmental stage-specific $\mathrm{Q}_{10}$ values (see text).

mass, and length values were $\log _{10}$ transformed prior to analysis to improve data distribution. Results are expressed as mean $\pm 1 \mathrm{SE}$.

\section{Results}

3.1. Species Comparisons. Eggs used in this study comprised one A. spinifera, five T. scripta, and four M. temminckii clutches (Table 1). Egg mass varied among clutches in the latter two species $(P<0.0001)$, but because a randomized block experimental design was employed, it did not vary among incubation temperatures $(A$. spinifera: $P=0.507 ; M$. temminckii: $P=0.145 ;$ T. scripta: $P=0.953)$.

Temperature affected incubation duration (Table 1), embryo $\mathrm{VO}_{2}$ (Figures 1,2 ) and total $\mathrm{O}_{2}$ consumed (Figure 3 ) in all three species. However, temperature affected incubation duration differently among the three species. The $4^{\circ} \mathrm{C}$ difference experienced by eggs incubated at $26.5^{\circ}$ compared to $30.5^{\circ} \mathrm{C}$ produced $31 \%$ and $28 \%$ differences in incubation time in A. spinifera and T. scripta, respectively, compared to just a $15 \%$ difference in $M$. temminckii. The effect of incubation temperature on $M$. temminckii incubation duration was an even smaller $4 \%$ across the $2^{\circ} \mathrm{C}$ span between $28.5-30.5^{\circ} \mathrm{C}$, compared to $19 \%$ and $12 \%$ in A. spinifera and T. scripta, respectively.
Despite low $\mathrm{VO}_{2}$ values during early development, precision of measurements was sufficient to detect differences among all three incubation temperatures at the first measurement in A. spinifera and T. scripta (days 2 and 5, resp.). Among M. temminckii embryos, mean $\mathrm{VO}_{2}$ at $26.5^{\circ}$ differed from that at $28.5^{\circ}$ and $30.5^{\circ} \mathrm{C}$ by day 7 and differed among all three temperatures by day $14(P<0.001$; Figure 1$)$.

Patterns in the magnitude of $\mathrm{VO}_{2 \max }$ among different incubation temperatures varied among species. Macrochelys temminckii embryos maintained at $26.5^{\circ}$ and $28.5^{\circ}$ had similar $\mathrm{VO}_{2 \max }(P=0.353)$ and were both greater than those incubated at $30.5^{\circ} \mathrm{C}(P<0.0001$; Figure $4(\mathrm{c}))$. In contrast, $\mathrm{VO}_{2 \max }$ among $T$. scripta embryos was lowest at $26.5^{\circ}(P<0.0001)$ and did not differ between $28.5^{\circ}$ and $30.5^{\circ} \mathrm{C}(P=0.054$; Figure $4(\mathrm{~b}))$. Finally, A. spinifera $\mathrm{VO}_{2 \max }$ was greatest at the intermediate incubation temperature $\left(28.5^{\circ}: P<0.0003\right)$ and did not differ at the extremes $(26.5-$ $30.5^{\circ} \mathrm{C}: P=0.157$; Figure $\left.4(\mathrm{a})\right)$.

The timing of $\mathrm{VO}_{2 \max }$ (expressed as \% total incubation duration) was unaffected by temperature for all three species (M. temminckii: 87.5\%, range $=82-97 \%, P=0.521 ; T$. scripta: $91 \%$, range $=84-97 \%, P=0.661 ;$ A spinifera: $87 \%$, range $=83-96 \%, P=0.060)$. These values were no doubt dependent on the timing of $\mathrm{VO}_{2}$ measurements, however. It should be noted that whereas M. temminckii and A. spinifera 


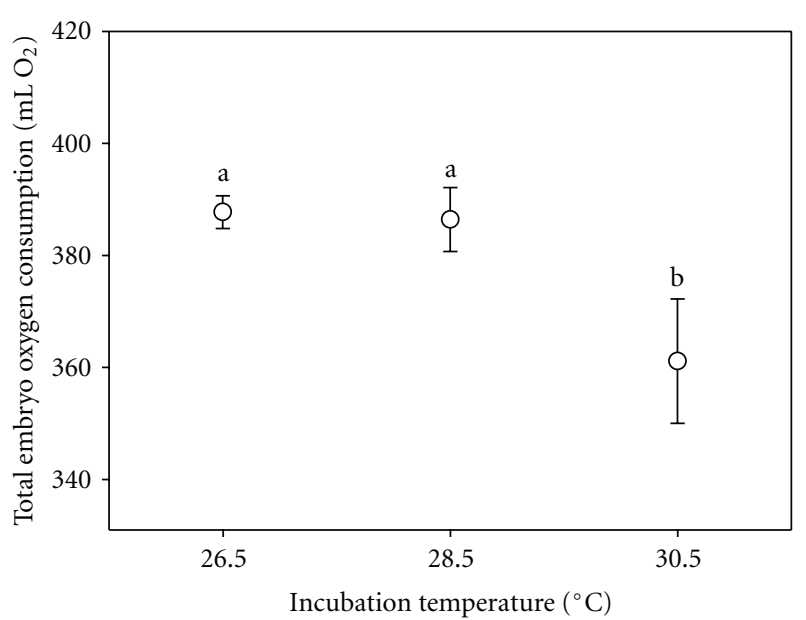

(a) Apalone spinifera

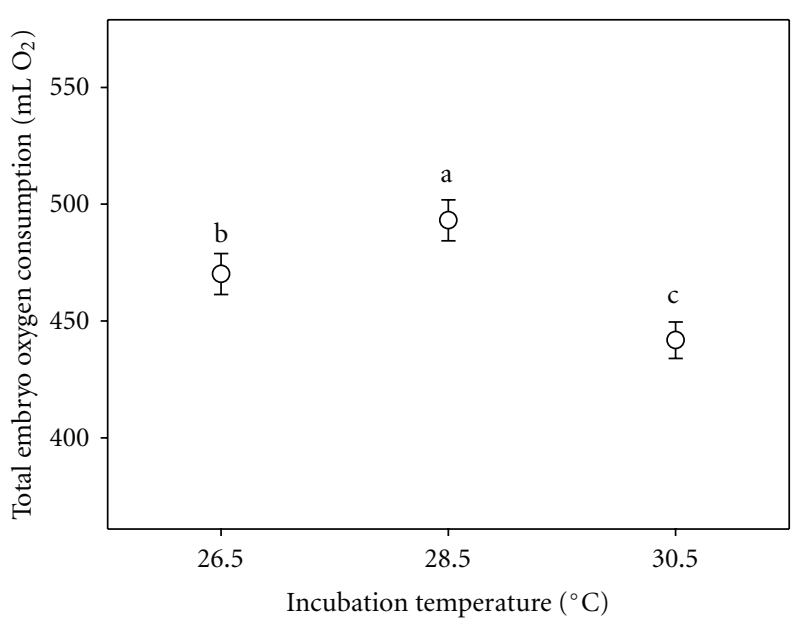

(b) Trachemys scripta

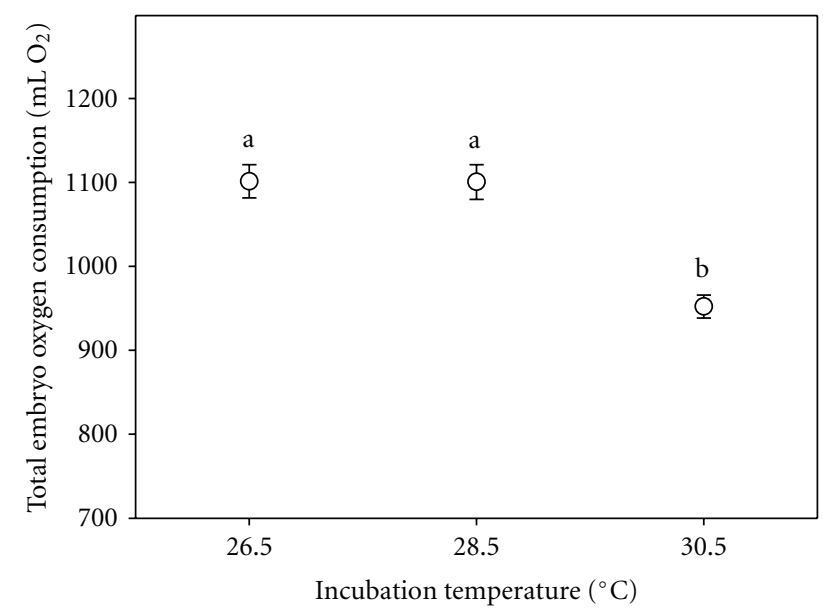

(c) Macrochelys temminckii

FIGURE 3: Comparison of the total volume of $\mathrm{O}_{2}$ consumed over the duration of incubation by embryos incubated at different constant temperatures. Lower case letters indicate treatment differences $(P<0.05)$. Error bars $= \pm 1 \mathrm{SE}$.

exhibited distinctly peaked embryo $\mathrm{VO}_{2}$ patterns, $\mathrm{VO}_{2 \max }$ among T. scripta tended to occur at the last measurement prior to hatching (Figure 1). The exceptions to this pattern were five out of 18 embryos incubated at $26.5^{\circ} \mathrm{C}$ that peaked at the penultimate $\mathrm{VO}_{2}$ measurement.

Total $\mathrm{O}_{2}$ consumption over the course of embryonic development was similar at $26.5^{\circ}$ and $28.5^{\circ} \mathrm{C}$ and lower at $30.5^{\circ} \mathrm{C}$ in A. spinifera and M. temminckii. By comparison, total $\mathrm{O}_{2}$ consumption in T. scripta was highest at $28.5^{\circ} \mathrm{C}$, intermediate at $26.5^{\circ} \mathrm{C}$ and lowest at $30.5^{\circ} \mathrm{C}$ (Figure 3).

3.2. Metabolic Compensation. $\mathrm{VO}_{2}$ measurements used for calculating $\mathrm{Q}_{10}$ values were selected based on their timing (targets: $0,33,67$, and $100 \%$ of incubation) and degree of overlap in the timing of $26.5^{\circ}$ and $30.5^{\circ} \mathrm{C}$ measurements when expressed as a proportion of incubation duration in order to closely match the developmental stages compared among embryos at different incubation temperatures (Figure 2 and Table 2). Among A. spinifera, $\mathrm{Q}_{10}$ was 4.0-69.5 for the first three stages. However, at approximately $95 \%$ development $\mathrm{Q}_{10}=1.2$, lower than expected in the absence of positive compensation. In comparison, T. scripta exhibited $\mathrm{Q}_{10} \mathrm{~s}$ between two and three during the initial two-thirds of development, and a similar decrease close to hatching $\left(\mathrm{Q}_{10}=1.4\right.$ at approximately $88 \%$ development $)$. In contrast, M. temminckii registered $\mathrm{Q}_{10}$ s less than two throughout development. $\mathrm{VO}_{2}$ measurements at $89 \%$ development produced a $\mathrm{Q}_{10}=0.7$.

3.3. Cost of Development. Although hatchling mass was not significantly different among incubation temperatures $(A$. spinifera: $P=0.983$; T. scripta: $P=0.065 ; M$. temminckii: $P=0.200$; Figure 5), temperature-induced differences were evident in mass conversion efficiency (Figure 6) and hatchling BCI (Figure 7) in T. scripta and M. temminckii, but not A. spinifera.

Hatchling mass scaled positively to egg mass in all three species. Trachemys scripta hatchling mass fit the equation $\mathrm{M}_{\text {hatchling }}=-0.04 \mathrm{M}_{\mathrm{egg}}{ }^{0.93}\left(r^{2}=0.32, P<0.0001\right)$, M. temminckii fit the equation $\mathrm{M}_{\text {hatchling }}=-0.05 \mathrm{M}_{\mathrm{egg}} 0.93$ 


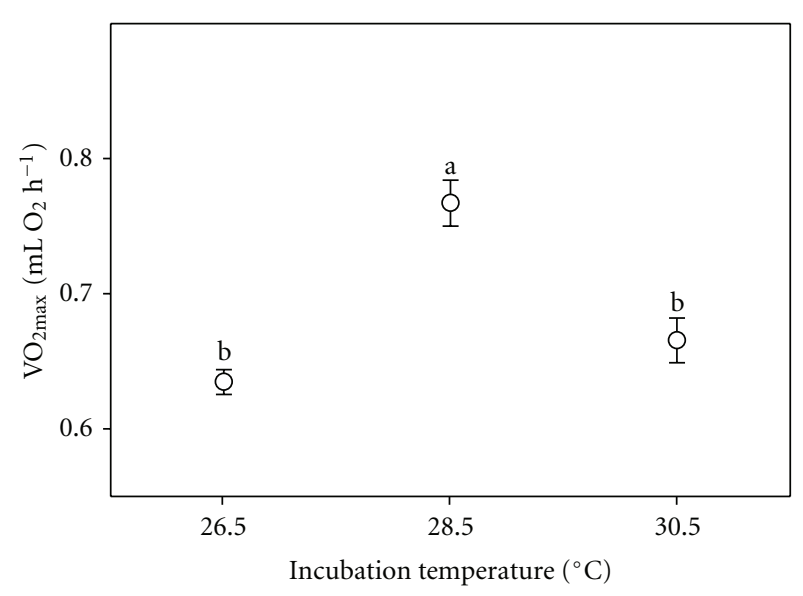

(a) Apalone spinifera

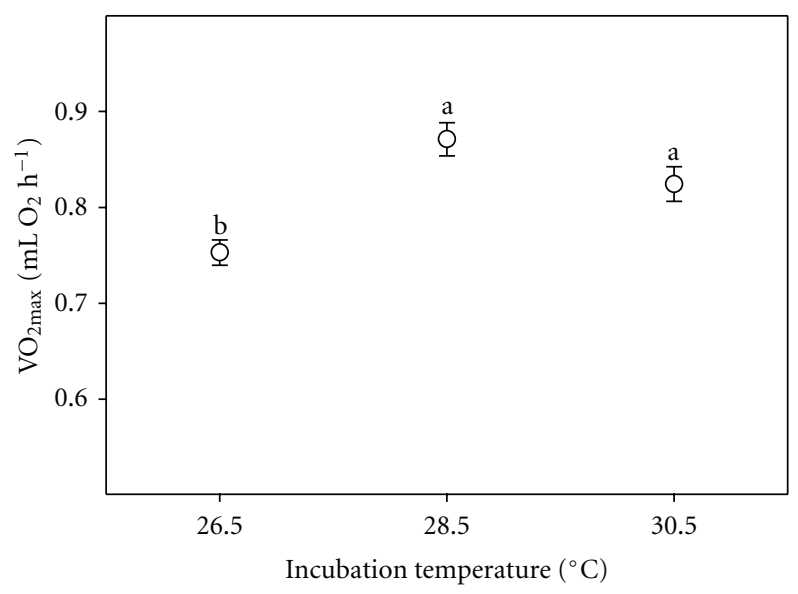

(b) Trachemys scripta

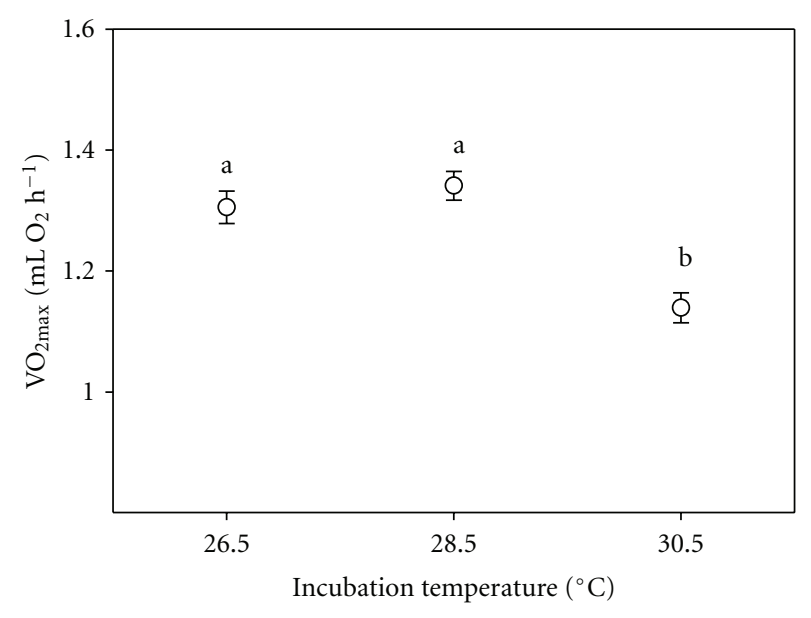

(c) Macrochelys temminckii

FIgURE 4: $\mathrm{VO}_{2 \max }$ of turtle embryos incubated at three temperatures. Lower case letters indicate treatment differences $(P<0.05)$. Error bars $= \pm 1 \mathrm{SE}$.

$\left(r^{2}=0.50, P<0.0001\right)$, and A. spinifera fit the equation $\mathrm{M}_{\text {hatchling }}=-0.13 \mathrm{M}_{\text {egg }}{ }^{0.92}\left(r^{2}=0.25, P=0.04\right)$. Mass conversion efficiency was unaffected by incubation temperature in A. spinifera $(P=0.93)$, was reduced at high temperatures in $M$. temminckii $(P=0.03)$, and was elevated at high temperatures in T. scripta $(P=0.02$; Figure 6$)$.

Hatchling BCI, expressed as the relationship between $\log _{10}$-transformed length and mass, did not differ across incubation temperatures in A. spinifera (Figure 7(a)). BCI of hatchlings was not different at $26.5^{\circ}$ and $28.5^{\circ} \mathrm{C}$ in T. scripta, and was higher at both these temperatures in comparison to hatchlings from $30.5^{\circ} \mathrm{C}$ (Figure 7(b)). Among M. temminckii, $\mathrm{BCI}$ was greatest at $26.5^{\circ}$, intermediate at $28.5^{\circ}$, and lowest at $30.5^{\circ} \mathrm{C}$ (Figure $7(\mathrm{c})$ ).

\section{Discussion}

Interspecific variation was evident in the effects temperature had on stage-specific $\mathrm{Q}_{10}$ values, $\mathrm{O}_{2 \text { total }}, \mathrm{VO}_{2 \max }$, hatchling size, and hatchling composition (BCI). However, broadscale consistency in the direction and timing of observed patterns suggest that incubation temperature influenced embryo energetics and growth similarly among the three species.

Chemical reaction rates typically exhibit $\mathrm{Q}_{10} \mathrm{~s}$ of 2-3. Biological rates that fall below this range are often interpreted to be indicative of temperature compensation, whereas higher values indicate inverse compensation, or hypersensitivity to temperature [51]. Progressively decreasing $\mathrm{Q}_{10} \mathrm{~s}$ over the course of embryonic development have been observed in several poikilotherms, including a turtle (Emys orbicularis; [35]), and two fishes (Danio rerio and Salmo gairdneri; $[52,53]$. This pattern frequently has been proposed to reflect greater thermal compensation as development progresses.

$\mathrm{Q}_{10}$ values were highly variable both within and among species and did not neatly fit a negative correlation with embryonic development. However, as in previous studies, $\mathrm{Q}_{10}$ was consistently lower near the conclusion of embryonic development than during earlier stages in all three species.

Macrochelys temminckii incubated at $30.5^{\circ} \mathrm{C}$ consumed less oxygen than those at lower temperatures and exhibited $\mathrm{VO}_{2 \max }$ lower than that of turtles at $28.5^{\circ} \mathrm{C}$ and similar to 
TABLE 2: $\mathrm{VO}_{2} \mathrm{Q}_{10}$ values calculated at different stages of embryonic development in three turtle species. Stages are expressed as \% of total incubation duration, followed by the number of days since oviposition. $\mathrm{Q}_{10}$ values were calculated from $\mathrm{VO}_{2} \mathrm{~s}$ of turtles incubated at 26.5 and $30.5^{\circ} \mathrm{C}$.

\begin{tabular}{|c|c|c|c|c|c|c|c|c|c|}
\hline \multirow{4}{*}{$\frac{\text { Species }}{\text { A. spinifera }}$} & \multirow{4}{*}{$\begin{array}{c}T_{\text {inc }} \\
26.5^{\circ} \\
30.5^{\circ}\end{array}$} & \multicolumn{8}{|c|}{ Stages (\% incubation duration, day of incubation) } \\
\hline & & \multicolumn{2}{|r|}{1} & \multicolumn{2}{|c|}{2} & \multicolumn{2}{|c|}{3} & \multicolumn{2}{|c|}{4} \\
\hline & & $2.6 \%, 2$ & $\mathrm{Q}_{10}=69.54$ & $30.0 \%, 23$ & $\mathrm{Q}_{10}=3.98$ & $66.6 \%, 51$ & $\mathrm{Q}_{10}=5.57$ & $94.0 \%, 72$ & $\mathrm{Q}_{10}=1.24$ \\
\hline & & $3.8 \%, 2$ & 0.07 & $30.2 \%, 16$ & 0.00 & $69.8 \%, 37$ & ונסני & $96.2 \%, 51$ & \\
\hline \multirow{2}{*}{ T. scripta } & $26.5^{\circ}$ & $7.1 \%, 5$ & \multirow{2}{*}{$\mathrm{Q}_{10}=2.14$} & $36.7 \%, 26$ & \multirow{2}{*}{$\mathrm{Q}_{10}=2.30$} & $66.3 \%, 47$ & \multirow{2}{*}{$\mathrm{Q}_{10}=2.37$} & $86.1 \%, 61$ & \multirow{2}{*}{$\mathrm{Q}_{10}=1.39$} \\
\hline & $30.5^{\circ}$ & $9.7 \%, 5$ & & $36.7 \%, 19$ & & $63.7 \%, 33$ & & $90.7 \%, 47$ & \\
\hline \multirow{2}{*}{ M. temminckii } & $26.5^{\circ}$ & $7.6 \%, 7$ & \multirow{2}{*}{$\mathrm{Q}_{10}=1.38$} & $37.5 \%, 35$ & \multirow{2}{*}{$\mathrm{Q}_{10}=1.72$} & $67.5 \%, 63$ & \multirow{2}{*}{$\mathrm{Q}_{10}=1.98$} & $89.8 \%, 84$ & \multirow{2}{*}{$\mathrm{Q}_{10}=0.67$} \\
\hline & $30.5^{\circ}$ & $8.9 \%, 7$ & & $35.7 \%, 28$ & & $71.1 \%, 56$ & & $88.9 \%, 70$ & \\
\hline
\end{tabular}

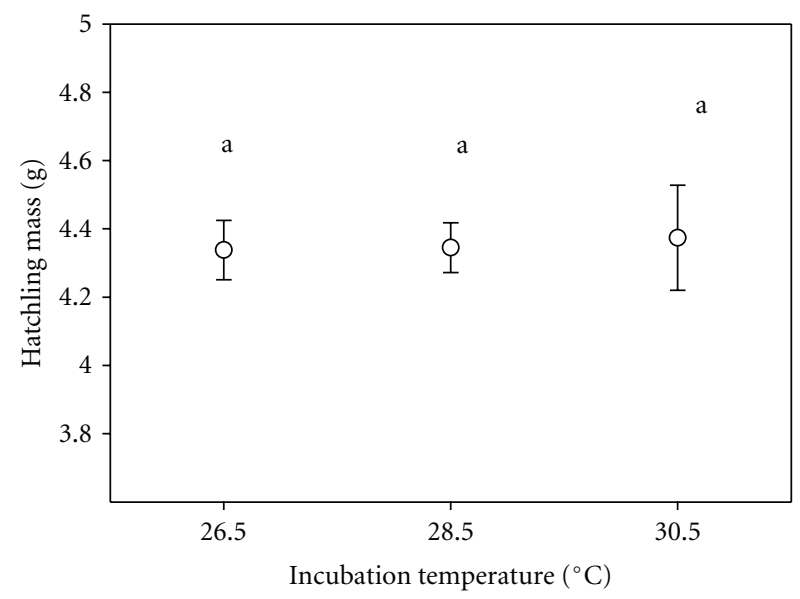

(a) Apalone spinifera

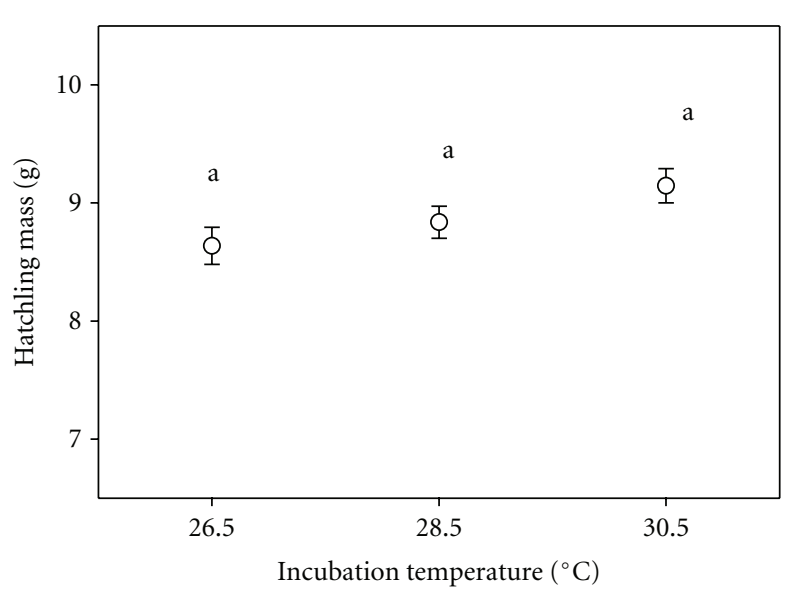

(b) Trachemys scripta

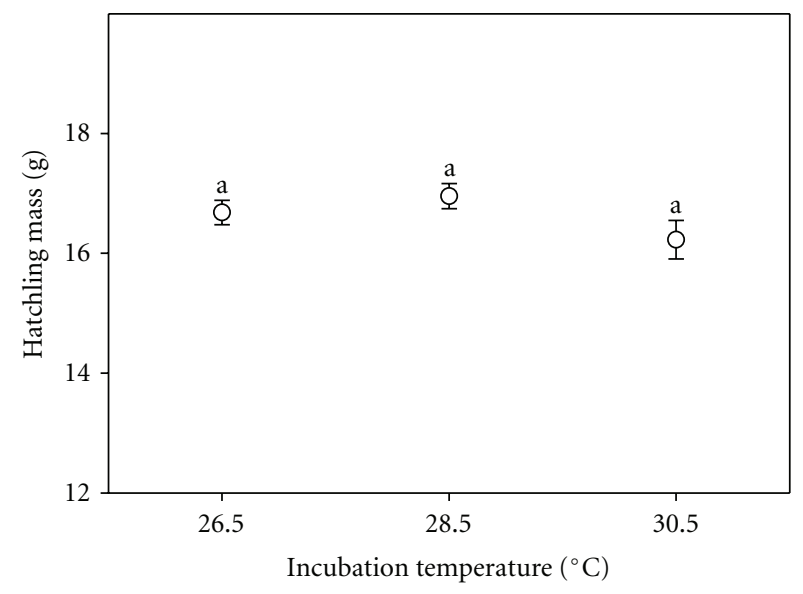

(c) Macrochelys temminckii

FIGURE 5: Mass of hatchlings incubated at different constant incubation temperatures. Lower case letters indicate treatment differences $(P<0.05)$. Error bars $= \pm 1$ SE.

those at $26.5^{\circ} \mathrm{C}$. Such results could stem from metabolic compensation to temperature, ultimately resulting in greater efficiency in the conversion of yolk to metabolically active tissue. Although it was infeasible in this study to sacrifice embryos or hatchlings to directly measure yolk : tissue ratios, evidence from $\mathrm{Q}_{10}$ s and hatchling size support an alternative conclusion: though incubation temperature produced minimal differences in hatchling mass, those from the highest temperature exhibited lower BCIs and were, therefore, morphometrically smaller after correcting for variation in 


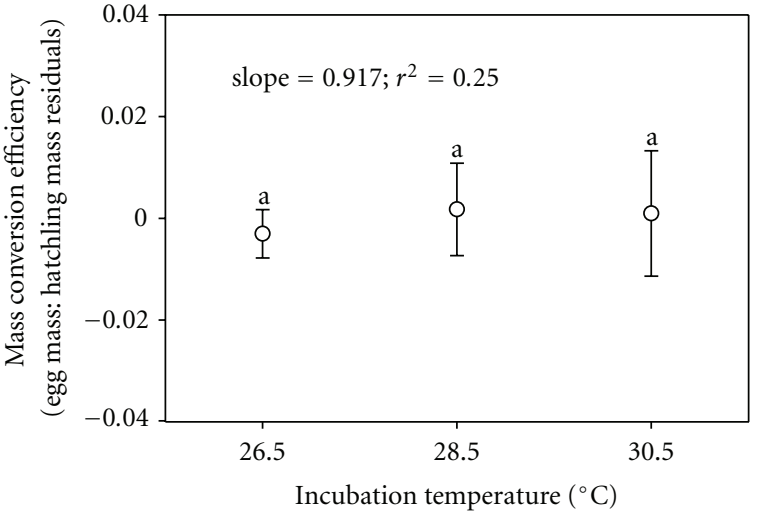

(a) Apalone spinifera

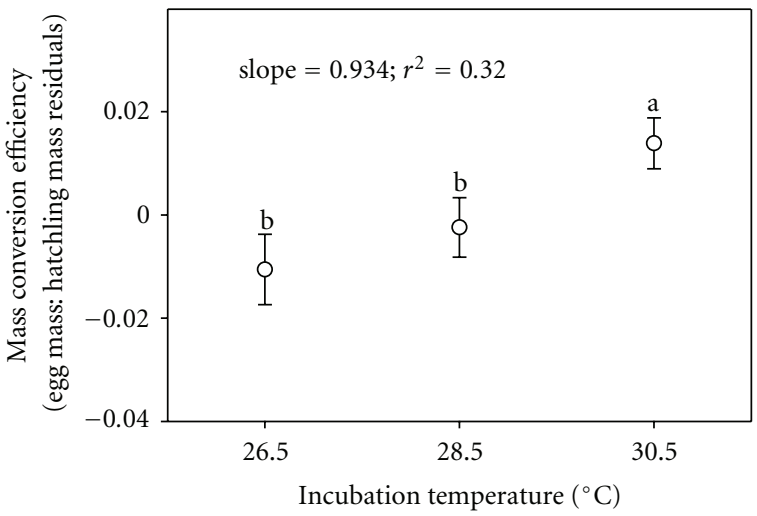

(b) Trachemys scripta

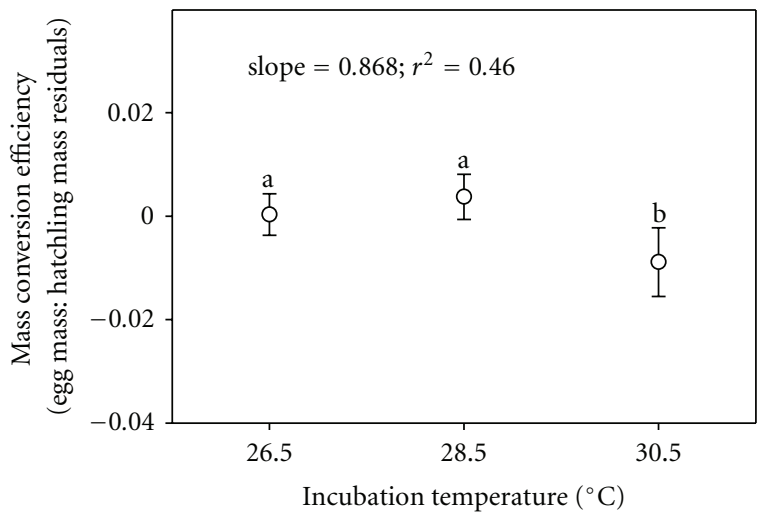

(c) Macrochelys temminckii

FIGURE 6: Differences in hatchling mass corrected for differences in initial egg mass. Values were calculated from L-S regression residuals from a log-log plot of hatchling mass against initial egg mass. Lower case letters indicate treatment differences $(P<0.05)$. Error bars $= \pm 1$ SE.

mass, than hatchlings from lower temperatures. Thus, we conclude that high temperatures negatively affected embryo growth, but that those smaller hatchlings may have emerged with large quantities of unmetabolized yolk, thus accounting for the lack of large differences in mass. The combination of these factors suggests that less metabolically active tissue was present in high incubation temperature hatchlings, resulting in lower $\mathrm{VO}_{2}$ even in the absence of metabolic compensation.

The effects of high incubation temperature on $\mathrm{VO}_{2}$ and $\mathrm{O}_{2 \text { total }}$ in T. scripta and $A$. spinifera were similar to those in $M$. temminckii. At $30.5^{\circ} \mathrm{C}, \mathrm{VO}_{2 \max }$ was lower than at $28.5^{\circ} \mathrm{C}$ (though not significantly so among $T$. scripta) and hatchlings at $30.5^{\circ} \mathrm{C}$ exhibited lower $\mathrm{O}_{2 \text { total }}$ than conspecifics at lower temperatures. Whereas $M$. temminckii hatchlings from $30.5^{\circ} \mathrm{C}$ incubation temperature were slightly lighter than from lower temperatures, no such negative massincubation temperature relationship was evident in the two other species, and T. scripta from the highest temperature were actually slightly heavier. However, BCIs were lowest at $30.5^{\circ} \mathrm{C}$ in all three species (though not significantly so in $A$. spinifera), suggesting that, as appears likely in $M$. temminckii, body length was smaller and the proportion of mass composed of metabolically inactive yolk was higher among hatchlings that developed at high temperatures. Evidence supports such a negative correlation between quantity of residual yolk and the length-to-mass relationship in another turtle, Chelonia mydas, in which posthatching yolk mass and hatchling yolk-free mass were measured [40].

These results suggest, albeit indirectly, that incubation temperature produced differences in yolk-free mass. This conclusion is consistent with a number of turtle and squamate studies that have shown a negative correlation between incubation temperature and yolk-free tissue mass [37, 40, 48, 54-56]. Although we cannot reject positive metabolic compensation as an additional factor contributing to the observed $\mathrm{VO}_{2}$ patterns, there is precedence for drawing the more parsimonious conclusion that differences in yolk-free size alone produced the observed incubation temperature differences without a compensatory response to temperature acclimation during incubation [55].

The differences in the effects of temperature on hatchling size and yolk reserves suggest that the costs and benefits of developing at relatively high temperatures differ among the three species studied. It has been demonstrated in several lizard species that large hatchling size increases survival, presumably by increasing foraging efficiency and decreasing susceptibility to predation [57-64]. Studies suggest that size affects aquatic turtle hatchling survival, as well [65-69]. However, hatchling size may affect fitness in subtler ways. It is also generally assumed that large postembryonic yolk 


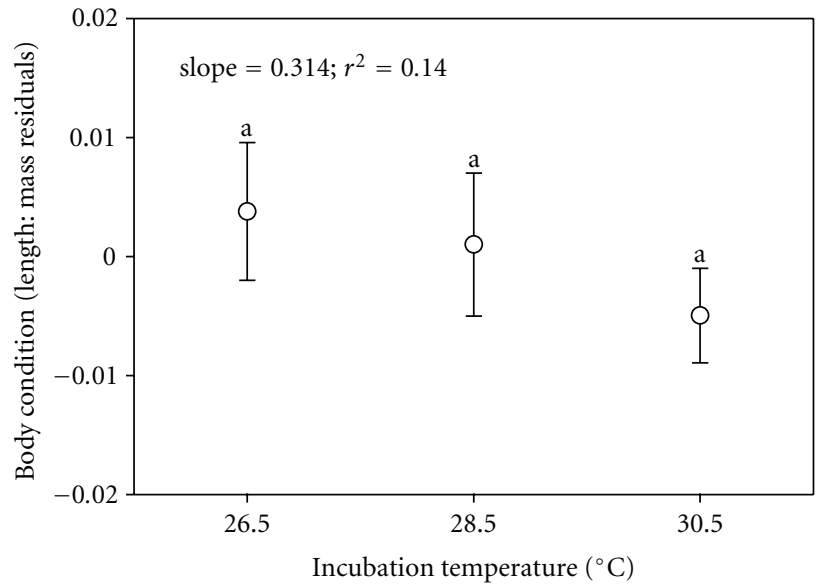

(a) Apalone spinifera

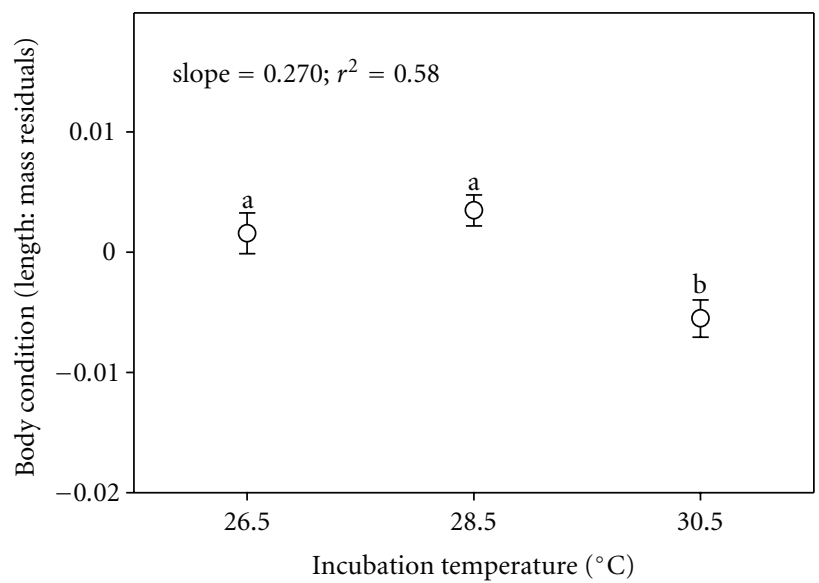

(b) Trachemys scripta

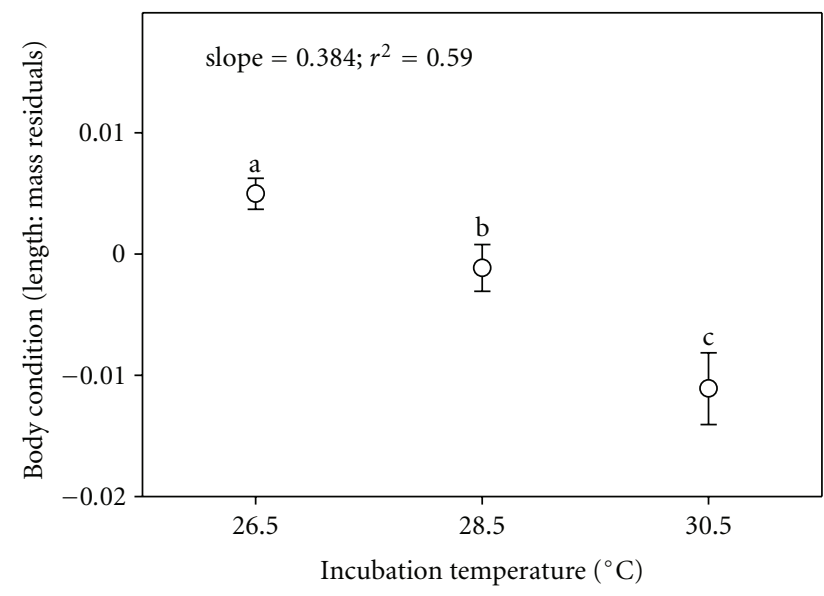

(c) Macrochelys temminckii

FIGURE 7: Hatchling body composition indices calculated as residuals from a L-S regression from a log-log plot of body length on mass. Lower case letters indicate treatment differences $(P<0.05)$. Error bars $= \pm 1 \mathrm{SE}$.

reserves increase fitness, either by increasing the time a hatchling can survive before eating or, similarly, increasing winter survival in species that delay emergence until spring $[70,71]$.

Trachemys scripta exhibited evidence of retaining more residual yolk at $30.5^{\circ} \mathrm{C}$ than at lower incubation temperatures. Therefore, development at high incubation temperature may confer the benefits of additional energy reserves, even at the cost of smaller body length. Because females are produced exclusively at $30.5^{\circ} \mathrm{C}$ [42], and female T. scripta attain sexual maturity at a larger size than do males [42], this difference in hatchling composition lends support to the hypothesis that temperature-dependent sex determination evolved due to asymmetrical benefits to the sexes of developing at different temperatures [9]. Similar patterns were observed in A. spinifera, and so the benefits of developing at high incubation temperatures are likely similar. However, males and females do not differentially benefit, as this species exhibits genetic sex determination.

As with T. scripta and A. spinifera, evidence suggests that $M$. temminckii that were incubated at high temperatures retained relatively large yolk residuals. This potential benefit to survival was offset by the fact that hatchlings were morphometrically smaller at $30.5^{\circ} \mathrm{C}$. Additionally, M. temminckii embryo mortality was high at $30.5^{\circ} \mathrm{C}[43]$, whereas hatching success was unaffected by incubation temperature in the two other species. Therefore, it is unlikely that the phenotype expressed at high temperatures by M. temminckii hatchlings enhances fitness, but is instead the result of limitations on growth at high temperatures.

Future research investigating the ways that incubation temperature affects embryo energetics and hatchling body composition is needed to differentiate costs associated with growth and maintenance during development and to assess the relative benefits to hatchlings of maximizing body size versus retaining yolk for sustaining posthatching metabolism. A large body of literature exists on the effects of incubation temperature on hatchling turtle size and growth [1115], but more detailed analyses of temperature's effect on the proportions of tissue and yolk that comprise hatchling mass will lend greater insight into the role incubation temperature plays in affecting survival and, ultimately, fitness. 


\section{Acknowledgments}

The authors thank Sequoyah National Wildlife Refuge and Tishomingo National Fish Hatchery for providing turtle eggs for this research. S. Watkins, P. Widder, and E. Ligon assisted with measuring metabolic rates. The paper benefited greatly from comments by J. Bidwell, S. Fox, and M. Payton. Financial support was provided by the Oklahoma State University Environmental Institute, Association for the Study of Ichthyology and Herpetology, Chicago Herpetological Society, Chelonian Research Foundation, Society of Integrative and Comparative Biology, and Sigma Xi. Experiments reported in this study comply with the current United States laws on animal experimentation.

\section{References}

[1] A. Clarke, "Is there a universal temperature dependence of metabolism?” Functional Ecology, vol. 18, no. 2, pp. 252-256, 2004.

[2] J. F. Gillooly, J. H. Brown, G. B. West, V. M. Savage, and E. L. Charnov, "Effects of size and temperature on metabolic rate," Science, vol. 293, no. 5538, pp. 2248-2251, 2001.

[3] M. E. Feder and G. E. Hofmann, "Heat-shock proteins, molecular chaperones, and the stress response: evolutionary and ecological physiology," Annual Review of Physiology, vol. 61, pp. 243-282, 1999.

[4] J. R. Hazel and C. L. Prosser, "Molecular mechanisms of temperature compensation in poikilotherms," Physiological Reviews, vol. 54, no. 3, pp. 620-677, 1974.

[5] J. J. Lin, S. MacLeod, and C. M. Kuo, "Qualitative and quantitative strategies of thermal adaptation of grass carp (Ctenopharyngodon idella) cytoplasmic malate dehydrogenases," Fish Physiology and Biochemistry, vol. 15, no. 1, pp. 71-81, 1996.

[6] G. N. Somero, "Adaptation of enzymes to temperature: searching for basic 'strategies," Comparative Biochemistry and Physiology, vol. 139, no. 3, pp. 321-333, 2004.

[7] C. L. Morjan, "Variation in nesting patterns affecting nest temperatures in two populations of painted turtles (Chrysemys picta) with temperature-dependent sex determination," Behavioral Ecology and Sociobiology, vol. 53, no. 4, pp. 254261, 2003.

[8] J. J. Bull and E. L. Charnov, "Enigmatic sex ratios," Evolution, vol. 43, pp. 1561-1566, 1989.

[9] D. Crews, J. M. Bergeron, J. J. Bull et al., "Temperaturedependent sex determination in reptiles: proximate mechanisms, ultimate outcomes, and practical applications," Developmental Genetics, vol. 15, no. 3, pp. 297-312, 1994.

[10] C. Ciofi and I. R. Swingland, "Environmental sex determination in reptiles," Applied Animal Behaviour Science, vol. 51, no. 3-4, pp. 251-265, 1997.

[11] R. J. Brooks, M. L. Bobyn, D. A. Galbraith, J. A. Layfield, and E. G. Nancekivell, "Maternal and environmental influences on growth and survival of embryonic and hatchling snapping turtles (Chelydra serpentina)," Canadian Journal of Zoology, vol. 69, no. 10, pp. 2667-2676, 1991.

[12] J. R. Spotila, L. D. Spotila, and N. F. Kaufer, "Molecular mechanisms of TSD in reptiles: a search for the magic bullet," Journal of Experimental Zoology, vol. 270, no. 1, pp. 117-127, 1994.

[13] W. M. Roosenburg and K. C. Kelley, "The effect of egg size and incubation temperature on growth in the turtle, Malaclemys terrapin," Journal of Herpetology, vol. 30, no. 2, pp. 198-204, 1996.

[14] S. O’Steen, "Embryonic temperature influences juvenile temperature choice and growth rate in snapping turtles Chelydra serpentina," The Journal of Experimental Biology, vol. 201, no. 3, pp. 439-449, 1998.

[15] J. P. Demuth, "The effects of constant and fluctuating incubation temperatures on sex determination, growth, and performance in the tortoise Gopherus polyphemus," Canadian Journal of Zoology, vol. 79, no. 9, pp. 1609-1620, 2001.

[16] W. G. Du and X. Ji, "The effects of incubation thermal environments on size, locomotor performance and early growth of hatchling soft-shelled turtles, Pelodiscus sinensis," Journal of Thermal Biology, vol. 28, no. 4, pp. 279-286, 2003.

[17] K. M. Ryan, J. R. Spotila, and E. A. Standora, "Incubation temperature and post-hatching growth and performance in snapping turtles," American Zoologist, vol. 30, article 112A, 1990.

[18] C. M. McKnight and W. H. N. Gutzke, "Effects of embryonic environment and of hatchling housing conditions on growth of young snapping turtles (Chelydra serpentina)," Copeia, vol. 1993, pp. 475-482, 1993.

[19] M. L. Bobyn and R. J. Brooks, "Interclutch and interpopulation variation in the effects of incubation conditions on sex, survival and growth of hatchling turtles (Chelydra serpentina)," Journal of Zoology, vol. 233, no. 2, pp. 233-257, 1994.

[20] T. Rhen and J. W. Lang, "Phenotypic plasticity for growth in the common snapping turtle: effects of incubation temperature, clutch, and their interaction," American Naturalist, vol. 146, no. 4, pp. 726-747, 1995.

[21] T. Rhen and J. W. Lang, "Temperature during embryonic and juvenile development influences growth in hatchling snapping turtles, Chelydra serpentina," Journal of Thermal Biology, vol. 24, no. 1, pp. 33-41, 1999.

[22] A. C. Steyermark and J. R. Spotila, "Effects of maternal identity and incubation temperature on snapping turtle (Chelydra serpentina) growth," Functional Ecology, vol. 15, no. 5, pp. 624632, 2001.

[23] D. A. Warner and R. Shine, "The adaptive significance of temperature-dependent sex determination: experimental tests with a short-lived lizard," Evolution, vol. 59, no. 10, pp. 22092221, 2005.

[24] F. J. Janzen, "The influence of incubation temperature and family on eggs, embryos, and hatchlings of the smooth softshell turtle (Apalone mutica)," Physiological Zoology, vol. 66, no. 3, pp. 349-373, 1993.

[25] F. J. Janzen, "Expermental evidence for the evolutionary significance of temperature-dependent sex determination," Evolution, vol. 49, no. 5, pp. 864-873, 1995.

[26] J. S. Doody, "A test of the comparative influences of constant and fluctuating incubation temperatures on phenotypes of hatchling turtles," Chelonian Conservation and Biology, vol. 3, pp. 529-531, 1999.

[27] S. O'Steen and F. J. Janzen, "Embryonic temperature affects metabolic compensation and thyroid hormones in hatchling snapping turtles," Physiological and Biochemical Zoology, vol. 72, no. 5, pp. 520-533, 1999.

[28] A. C. Steyermark and J. R. Spotila, "Effects of maternal identity and incubation temperature on snapping turtle (Chelydra serpentina) metabolism," Physiological and Biochemical Zoology, vol. 73, no. 3, pp. 298-306, 2000. 
[29] D. T. Booth, "Influence of incubation temperature on hatchling phenotype in reptiles," Physiological and Biochemical Zoology, vol. 79, no. 2, pp. 274-281, 2006.

[30] M. B. Thompson, "Patterns of metabolism in embryonic reptiles," Respiration Physiology, vol. 76, no. 2, pp. 243-256, 1989.

[31] M. B. Thompson, "Oxygen consumption and energetics of development in eggs of the leatherback turtle, Dermochelys coriacea," Comparative Biochemistry and Physiology A, vol. 104, no. 3, pp. 449-453, 1993.

[32] G. F. Birchard and C. L. Reiber, "Growth, metabolism, and chorioallantoic vascular density of developing snapping turtles (Chelydra serpentina): influence of temperature," Physiological Zoology, vol. 68, no. 5, pp. 799-811, 1995.

[33] M. J. Angilletta, R. S. Winters, and A. E. Dunham, “Thermal effects on the energetics of lizard embryos: implications for hatchling phenotypes," Ecology, vol. 81, no. 11, pp. 2957-2968, 2000.

[34] D. T. Booth, "Incubation of eggs of the Australian broadshelled turtle, Chelodina expansa (Testudinata: Chelidae), at different temperatures: effects on pattern of oxygen consumption and hatchling morphology," Australian Journal of Zoology, vol. 48, no. 4, pp. 369-378, 2000.

[35] I. G. Vladimirova, T. A. Alekseeva, and M. V. Nechaeva, "Effect of temperature on the rate of oxygen consumption during the second half of embryonic and early postembryonic development of European pond turtle Emys orbicularis (Reptilia: Emydidae)," Biology Bulletin, vol. 32, no. 5, pp. 484-489, 2005.

[36] I. G. Vladimirova, T. A. Alekseeva, and M. V. Nechaeva, "Growth and oxygen consumption in embryonic and early postembryonic development of European pond turtle Emys orbicularis (Reptilia: Emydidae)," Biology Bulletin, vol. 32, no. 2, pp. 172-178, 2005.

[37] P. J. Whitehead and R. S. Seymour, "Patterns of metabolic rate in embryonic crocodilians Crocodylus johnstoni and Crocodylus porosus," Physiological Zoology, vol. 63, pp. 334-352, 1990.

[38] A. Leshem, A. Ar, and R. A. Ackerman, "Growth, water, and energy metabolism of the soft-shelled turtle (Trionyx triunguis) embryo: effects of temperature," Physiological Zoology, vol. 64, pp. 568-594, 1991.

[39] D. T. Booth, "Incubation of turtle eggs at different temperatures: do embryos compensate for temperature during development?" Physiological Zoology, vol. 71, no. 1, pp. 23-26, 1998.

[40] D. T. Booth and K. Astill, "Incubation temperature, energy expenditure and hatchling size in the green turtle (Chelonia mydas), a species with temperature-sensitive sex determination," Australian Journal of Zoology, vol. 49, no. 4, pp. 389-396, 2001.

[41] P. W. Hochachka and G. N. Someri, Strategies of Biochemical Adaptation, Saunders, Philadelphia, Pa, USA, 1973.

[42] C. H. Ernst, J. E. Lovich, and R. W. Barbour, Turtles of the United States and Canada, Smithsonian Institute Press, Washington, DC, USA, 1994.

[43] D. B. Ligon and M. B. Lovern, "Temperature effects during early life stages of the alligator snapping turtle (Macrochelys temminckii)," Chelonian Conservation and Biology, vol. 8, no. 1, pp. 74-83, 2009.

[44] M. A. Ewert, D. R. Jackson, and C. E. Nelson, "Patterns of temperature-dependent sex determination in turtles," Journal of Experimental Zoology, vol. 270, pp. 3-15, 1994.

[45] X. Ji, F. Chen, W. G. Du, and H. L. Chen, "Incubation temperature affects hatchling growth but not sexual phenotype in the
Chinese soft-shelled turtle, Pelodiscus sinensis (Trionychidae)," Journal of Zoology, vol. 261, no. 4, pp. 409-416, 2003.

[46] M. A. Ewert and J. M. Legler, "Hormonal induction of oviposition in turtles," Herpetologica, vol. 34, pp. 314-318, 1978.

[47] G. J. W. Webb, S. C. Manolis, P. J. Whitehead, and K. Dempsey, "The possible relationship between embryo orientation, opaque banding and the dehydration of albumen in crocodile eggs," Copeia, vol. 1987, pp. 252-257, 1987.

[48] G. C. Packard, M. J. Packard, K. Miller, and T. J. Boardman, "Influence of moisture, temperature, and substrate on snapping turtle eggs and embryos," Ecology, vol. 68, no. 4, pp. 983993, 1987.

[49] D. Vleck, "Measurement of $\mathrm{O}_{2}$ consumption, $\mathrm{CO}_{2}$ production, and water vapor production in a closed system," Journal of Applied Physiology, vol. 62, no. 5, pp. 2103-2106, 1987.

[50] C .C. Peterson, "Paradoxically low metabolic rate of the diurnal gecko Rhoptropus afer," Copeia, vol. 1990, pp. 233-237, 1990.

[51] R. E. Gatten, "Aerobic metabolism in snapping turtles, Chelydra serpentina, after thermal acclimation," Comparative Biochemistry and Physiology A, vol. 61, no. 2, pp. 325-337, 1978.

[52] T. A. Alekseeva, "Effect of temperature on oxygen consumption by rainbow trout," Ontogenez, vol. 18, pp. 308-311, 1987.

[53] W. R. Barrionuevo and W. W. Burggren, " $\mathrm{O}_{2}$ consumption and heart rate in developing zebrafish (Danio rerio): influence of temperature and ambient $\mathrm{O}_{2}$," American Journal of Physiology, vol. 276, no. 2 45-2, pp. R505-R513, 1999.

[54] C. Díaz-Paniagua and M. Cuadrado, "Influence of incubation conditions on hatching success, embryo development and hatchling phenotype of common chameleon (Chamaeleo chamaeleon) eggs," Amphibia Reptilia, vol. 24, no. 4, pp. 429-440, 2003.

[55] M. J. Angilletta, V. Lee, and A. C. Silva, "Energetics of lizard embryos are not canalized by thermal acclimation," Physiological and Biochemical Zoology, vol. 79, no. 3, pp. 573-580, 2006.

[56] Z. H. Lin, X. Ji, L. G. Luo, and X. M. Ma, "Incubation temperature affects hatching success, embryonic expenditure of energy and hatchling phenotypes of a prolonged eggretaining snake, Deinagkistrodon acutus (Viperidae)," Journal of Thermal Biology, vol. 30, no. 4, pp. 289-297, 2005.

[57] G. W. Ferguson and C. H. Bohlen, "Demographic analysis: a tool for the study of natural selection of behavioral traits," in Behavior and Neurology of Lizards, N. Greenberg and P. D. Maclean, Eds., pp. 227-243, Department of Health, Education and Welfare, NIMH, Rockville, Md, USA, 1978.

[58] S. F. Fox, "Natural selection on behavioral phenotypes of the lizard Uta stansburiana," Ecology, vol. 59, pp. 834-847, 1978.

[59] I. R. Swingland and M. J. Coe, "The natural regulation of giant tortoise populations on Aldabra Atoll: recruitment," Philosophical Transactions of the Royal Society B, vol. 28, pp. 177188, 1979.

[60] G. W. Ferguson and S. F. Fox, "Annual variation of survival advantage of large juvenile side- blotched lizards, Uta stansburiana: its causes and evolutionary significance," Evolution, vol. 38, no. 2, pp. 342-349, 1984.

[61] G. C. Packard, "The physiological and ecological importance of water to embryos of oviparous reptiles," in Egg Incubation: Its Effects on Embryonic Development in Birds and Reptiles, D. C. Deeming and M. W. J. Ferguson, Eds., pp. 213-228, Cambridge University Press, Cambridge, Mass, USA, 1991.

[62] R. Van Damme, D. Bauwens, F. Brana, and R. F. Verheyen, "Incubation temperature differentially affects hatching time, egg survival, and hatchling performance in the lizard Podarcis muralis," Herpetologica, vol. 48, no. 2, pp. 220-228, 1992. 
[63] F. Braña and X. Ji, "Influence of incubation temperature on morphology, locomotor performance, and early growth of hatchling wall lizards (Podarcis muralis)," Journal of Experimental Zoology, vol. 286, no. 4, pp. 422-433, 2000.

[64] D. A. Warner and R. M. Andrews, "Laboratory and field experiments identify sources of variation in phenotypes and survival of hatchling lizards," Biological Journal of the Linnean Society, vol. 76, no. 1, pp. 105-124, 2002.

[65] A. Haskell, T. E. Graham, C. R. Griffin, and J. B. Hestbeck, "Size related survival of headstarted redbelly turtles (Pseudemys rubriventris) in Massachusetts," Journal of Herpetology, vol. 30 , no. 4, pp. 524-527, 1996.

[66] F. J. Janzen, J. K. Tucker, and G. L. Paukstis, "Experimental analysis of an early life-history stage: selection on size of hatchling turtles," Ecology, vol. 81, no. 8, pp. 2290-2304, 2000.

[67] F. J. Janzen, J. K. Tucker, and G. L. Paukstis, "Experimental analysis of an early life-history stage: avian predation selects for larger body size of hatchling turtles," Journal of Evolutionary Biology, vol. 13, no. 6, pp. 947-954, 2000.

[68] J. K. Tucker, "Body size and migration of hatchling turtles: inter- and intraspecific comparisons," Journal of Herpetology, vol. 34, no. 4, pp. 541-546, 2000.

[69] J. J. Kolbe and F. J. Janzen, "The influence of propagule size and maternal nest-site selection on survival and behaviour of neonate turtles," Functional Ecology, vol. 15, no. 6, pp. 772$781,2001$.

[70] J. D. Congdon, J. W. Gibbons, and J. L. Greene, "Parental investment in the chicken turtle (Deirochelys reticularia)," Ecology, vol. 64, no. 3, pp. 419-425, 1983.

[71] N. I. Filoramo and F. J. Janzen, "Effects of hydric conditions during incubation on overwintering hatchlings of the redeared slider turtle (Trachemys scripta elegans)," Journal of Herpetology, vol. 33, no. 1, pp. 29-35, 1999. 

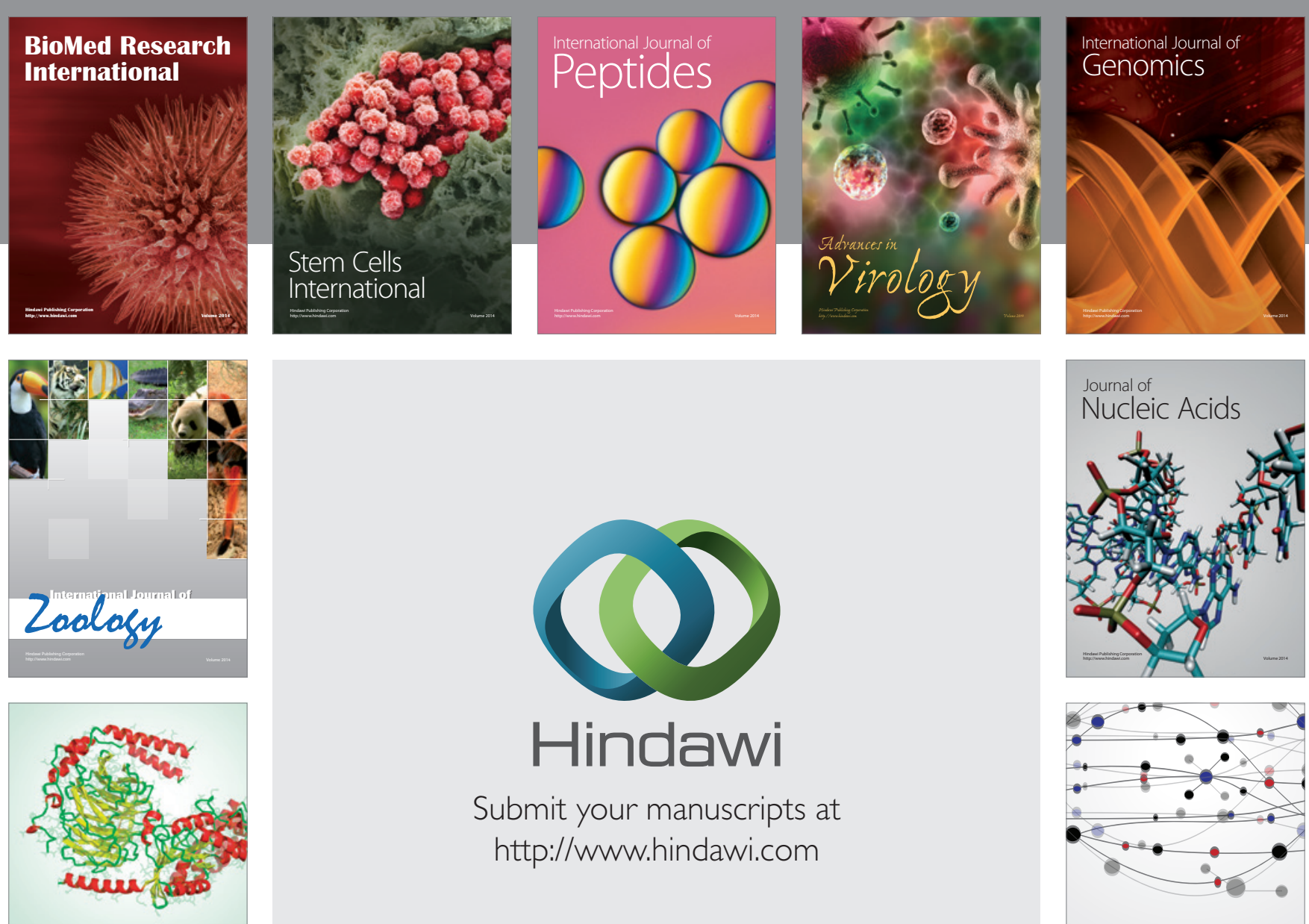

Submit your manuscripts at

http://www.hindawi.com

Signal ${ }^{\text {Jumal }}$ Transduction
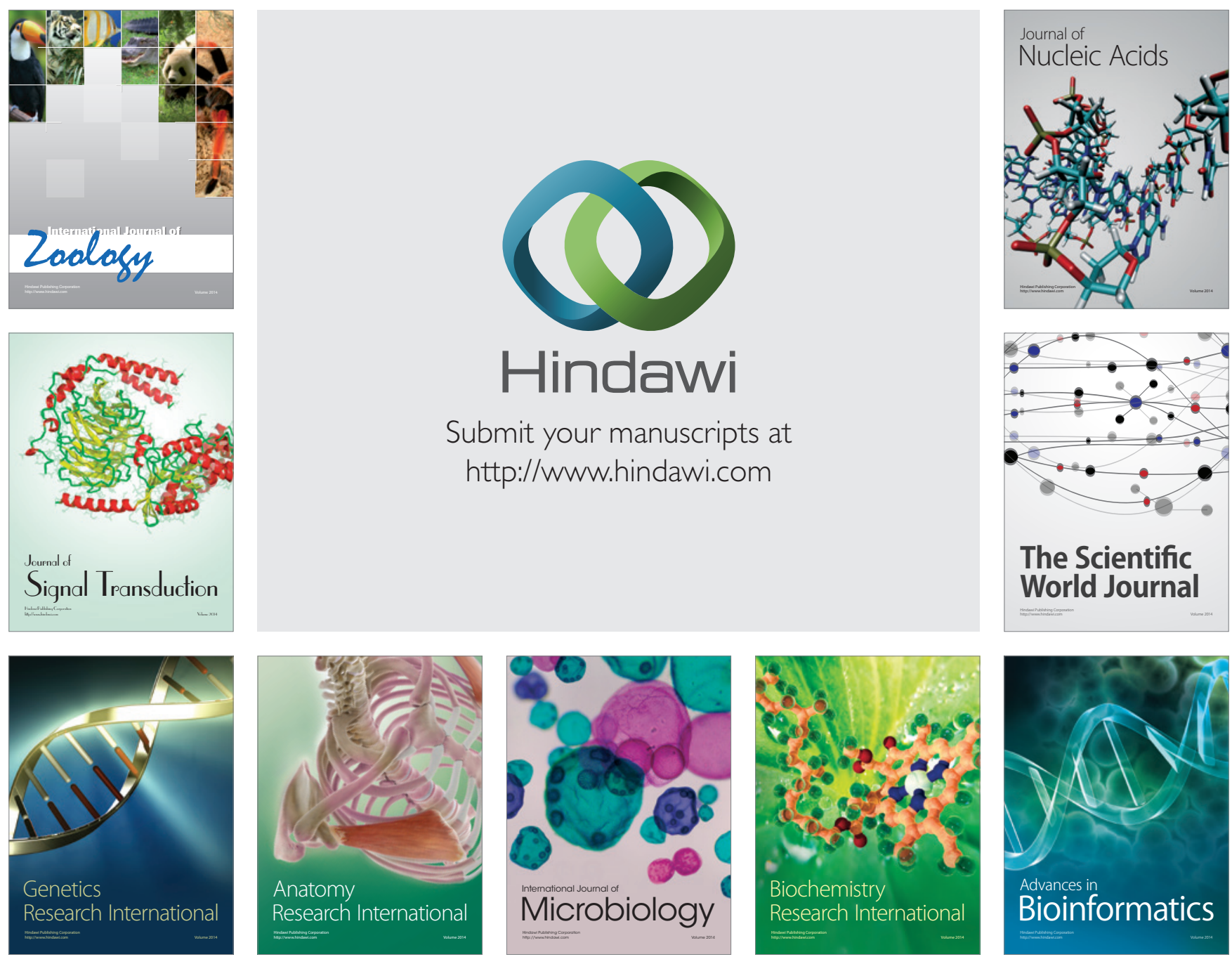

The Scientific World Journal
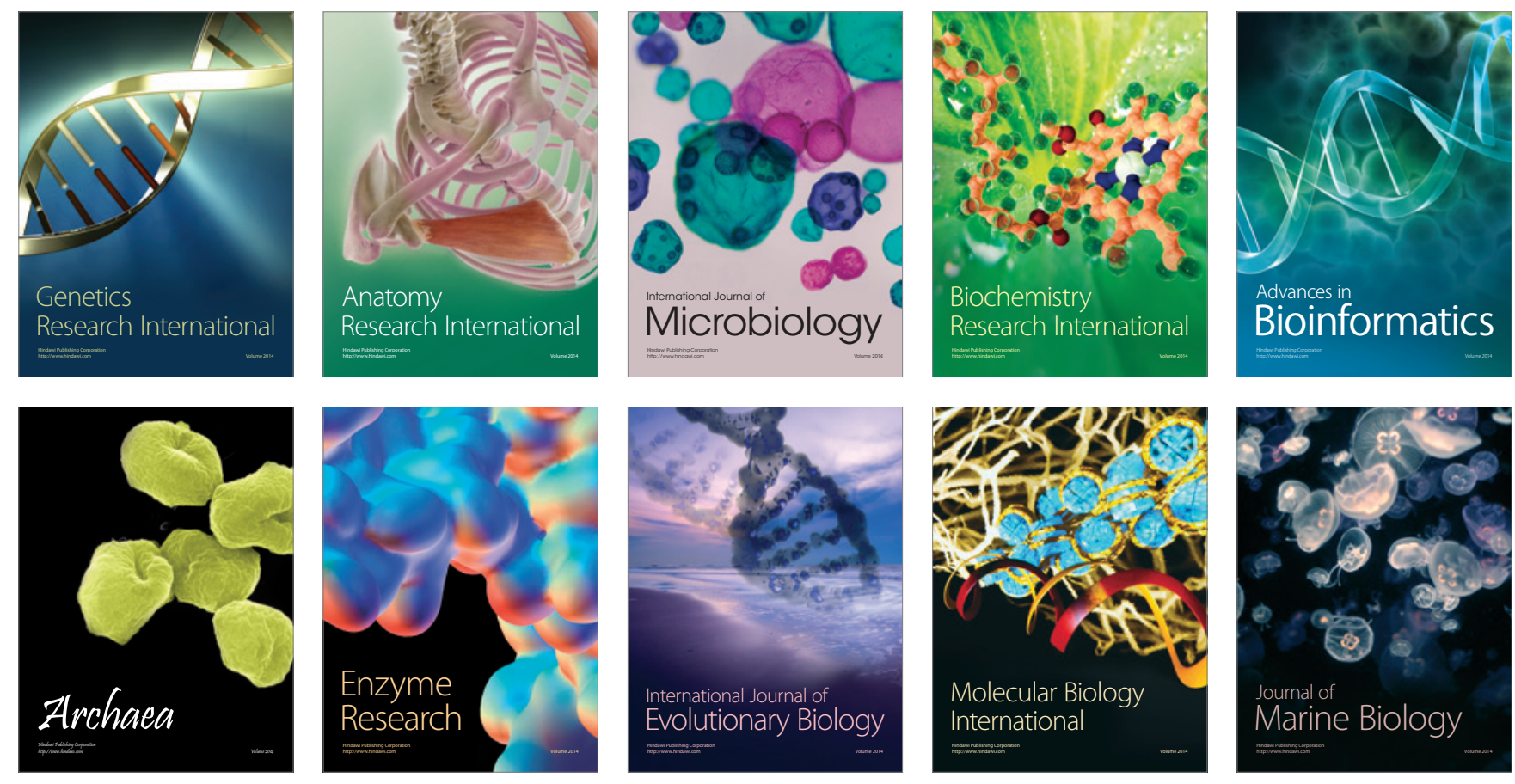